for choosing the best drug from a range of possibles for any one patient. Of the papers presented more had been engendered by cancer research than by any other single disease area. This is a fair representation of cellular pharmacology work since it is logical and practicable both to study the effects of compounds on normally and abnormally proliferating cells and to use compounds to study differences between such cells.

The Searle Lecture was delivered by L. J. Tolmach (Washington University) who spoke of his group's work on the enhancement of radiation effects on proliferating cells by various drugs used separately or together. He emphasised, as did several subsequent speakers, the relative ease of carrying out statistically satisfactory numbers of replicate experiments in cell culture, and of automating additions and removals of drugs. Drug-radiation interaction was discussed also by A. H. W. Nias (Belvidere Hospital, Glasgow) and papers on specific groups of compounds were presented by A. M. Creighton (Imperial Cancer Research Fund) and B. J. Phillips (Chester Beatty Research Institute).

The papers of R. I. Freshney (Beatson Institute, Glasgow) and J. A. Dickson (Royal Victoria Infirmary, Newcastle-upon-Tyne) dealt with the design of cell culture tests for measuring human tumour sensitivity to drugs, and the place of such tests in cancer therapy. They described the uses and limitations of such tests, and factors influencing the results, pointing out that a laboratory $\mathbf{L D}_{50}$ end point still meant $50 \%$ of surviving cells too.

A further group of four papers was on the subject of cardiac glycosides and electrophysiology experiments. These were by J. F. Lamb (University of St Andrews) and W. F. Dryden et al. (University of Strathclyde). There were two papers on anaesthetics and related compounds by L. J. Erkell (Göteborg) and A. G. Macdonald (Aberdeen). The latter paper led to comment on the validity of using non-mammalian material to investigate clinical problems, as did the paper of D. Brown, M. Balls and J. Pryor (University of East Anglia) who chose amphibian cell cultures for their relative functional longevity. The symposium title had been deliberately widened from "human" to "vertebrate" cells to generate discussion on the possibility of errors due to species difference on extrapolating from various types of in vitro tests to clinical situations. There was indeed much discussion on choice of culture material.

The action of parathyroid hormone on explanted bone rudiments was discussed by P. J. Gaillard (University of Leiden) in relation to hyperparathyroid conditions, and P. J. Hornsby and M. J. O'Hare (Chester Beatty Institute) described functional activity in cultured adrenal cells. The extraordinary biological properties of the cytochalasins were discussed by S. B. Carter (Imperial Chemical Industries, Macclesfield) who indicated their value in examining cellular processes as did $M$. de Brabander (Janssen Laboratories, Beerse).

Further areas where cell culture study was relevant to finding information about the compounds or the cells were reported in the papers on prostaglandins by $M$. Adolphe (Institute of Pharmacology, Paris), on in vitro antibody production by G. Harris (Kennedy Institute, London), on bacitracin by $\mathrm{M}$. Dawson (University of Strathclyde) and on colchicine and microtubules by D. Wheatley (University of Aberdeen).

\section{Mystery molecule in Japan}

from Sydney Shall

THE Japanese have taken poly(ADPribose) to their heart. Since much of the progress in this area of molecular biology comes from Japanese laboratories, this is understandable. The occasion of the first Oji International Seminar at Tomakomai, Hokkaido, was used by Professors Osamu Hayaishi (University of Kyoto) and Takashi Sugimura (University of Tokyo) to organise the third international meeting on poly(ADP-ribose) and the ADPribosylation of proteins (September 10-12), This very young field has progressed steadily over the last five years, but without success so far in two major respects: a simple method for measuring poly(ADP-ribose) in intact cells, and unequivocal evidence of its physiological function are both lacking.

This unusual chromosomal polymer has a composition almost identical to that of $\operatorname{poly}(\mathrm{A})$ but does not have a nucleic acid structure. It is made by a chromosomal enzyme for which NAD ${ }^{+}$ is the sole substrate. $\mathrm{NAD}^{+}$metabolism in cancer cells is unusual and poly(ADP-ribose) is thought to have some role in DNA replication and cell proliferation.

The highlights of the meeting included progress in the purification (5,000 times) of the poly(ADP-ribose) polymerase by Ueda and Hayaishi (University of Kyoto). The partially purified enzyme still requires both DNA and histones and makes short chains. The enzymes that degrade the polymer have been isolated and purified by $\mathbf{L}$. Burzio (Rockefeller University, New York) from testis, and by M. Tanaka, M. Miwa and T. Sugimura (University of Tokyo) from liver, thymus, Physarum polycephalum and from tobacco cells in culture.

There was considerable discussion following the paper by H. Hilz (University of Hamburg) as to whether the polymer is covalently attached to chromosomal protein. Hilz demonstrated that at least some of the polymer is covalently bonded to protein.

The most interesting report was the description by $T$. Kanai and $T$. Sugimura (Tokyo) of the preparation of antibodies to poly(ADP-ribose). They showed that with these antibodies a radioimmunoassay for poly(ADPribose) will be possible. The antibodies seem to be specific and do not crossreact with DNA, RNA or poly(A). In addition, they have detected antipoly(ADP-ribose) antibodies in the sera of human patients with the autoimmune diseases, especially in systemic lupus erythematosus. H. Hilz has estimated the amount of poly(ADP-ribose) in intact animals by an extremely carefully controlled, isotope dilution technique. Three important conclusions emerge: the polymer exists in intact cells, the amount of polymer was estimated in adult rat liver to be $5.25 \pm 0.09 \mathrm{nmol}$ of ADP-ribose residues per mg DNA; no striking difference in amount was found between adult rat liver, neonatal rat liver and Ehrlich ascites carcinoma cells. But in isolated nuclei there is a substantial difference in the content of mono(ADPribose) residues between adult and neonatal liver.

Other examples of ADP-ribosylation of proteins are very well authenticated. The modification and alteration of DNA-dependent RNA polymerase by ADP-ribosylation after T4 phage infection of Escherichia coli was clearly demonstrated by W. Zillig (Max-PlanckInstitut, Munich) and C. G. Goff (Medical Research Council, Cambridge). ADP-ribosylation of mammalian ribosomal elongation factor II by diphtheria toxin was dissected by C. Edson, K. Ueda and O. Hayaishi (University of Kyoto) and E. S. Maxwell (National Institutes of Healti, Bethesda). Both laboratories have so far failed to identify the ribosyl-protein bond in modified elongation factpr. But Maxwell showed the presence of an unusual amino acid in unmodified elongation factor II to which the ADPribose was apparently attached by the diphtheria toxin. Finally, K. Yoshihara (University of Nara, Japan) adduced evidence that the recently described chromatin-bound $\mathrm{Ca}^{2+}, \mathrm{Mg}^{2+}$ endonuclease is itself ADP-ribosylated.

The mysteries of poly(ADP-ribose) are steadily yielding to systematic attack. The elucidation of its function will radically alter our picture of the biology of the cell nucleus. 